\title{
The Role of the Mexican Executive \\ Women: The Impact of Personal Branding \\ and the Influence of the Erotic Capital \\ as a Secondary Brand Association: \\ An Abstract
}

\author{
Diana Davila and Tonatiuh Mendoza
}

\begin{abstract}
The present study explores the role of the Mexican executive women in using their erotic capital as brand association to build personal branding in the workplace. Using a qualitative method by means of the Delphi technique and consenting participants, the authors conducted the study in three stages with subsequent questionnaires. During the first stage, 50 in-depth interviews were submitted to women as managers in executive positions. The intention of the first questionnaire was to estimate the interquartile space. This approach assists in examining the phenomenon in its natural setting, providing considerable flexibility during interviews and observations. Four variables from erotic capital were considered: beauty, sexual attractiveness, social skills, and social presentation. The intention of the subsequent questionnaires was to reduce the interquartile space, that is, when the expert's opinion deviates from the group's opinion, requiring the median of the obtained responses. The second stage provides to each expert their colleagues' opinions and opens an interdisciplinary discussion to reach a consensus about the results and the conception of knowledge on the subject. The intention of the third consultation was to obtain a closer approximation to a consensus.

Results confirm that beauty and social presentation components influence erotic capital as part of the personal branding. Women executives cannot undervalue the weight of the erotic capital-mostly due to cultural reasons and strongly ingrained habits in our society-we tend to highlight logical, rational, and objective thinking aspects above capacities like intuition and emotional intelligence that are close to the perceptions that people have over personal image and erotic capital. From a theoretical perspective, the study provided further understanding of the value to create secondary personal brand associations such as beauty and social presentation, as an element of power and success for women in the workplace.
\end{abstract}

References Available Upon Request

D. Davila $(\bowtie) \cdot$ T. Mendoza

Universidad Anàhuac, Huixquilucan, Edo. de México, México

e-mail: diana.davilar@anahuac.mx; arielm@globalmarketingstaff.com

(C) Academy of Marketing Science 2019 